\title{
OS EFEITOS DO DISTANCIAMENTO SOCIAL NA CURRICULARIZAÇÃO EXTENSIONISTA DA DISCIPLINA DE DIREITO DAS FAMÍLIAS ${ }^{1}$
}

\author{
THE EFFECTS OF SOCIAL DISTANCING ON EXTENSIONIST \\ CURRICULARIZATION OF THE FAMILY LAW DISCIPLINE
}

\section{Bernadete Schleder dos Santos ${ }^{2}$}

\section{RESUMO}

O presente texto traz um relato sobre a experiência pedagógica realizada na prática extensionista da disciplina de Direito das Famílias, frente à necessidade da adaptação do planejamento das atividades previstas para o primeiro semestre de 2020, pela situação inesperada do distanciamento social imposto com o advento da pandemia provocada pelo Covid-19. A elaboração e publicação de um artigo coletivo de pesquisa, relacionando o tema do projeto de extensão com a inesperada realidade, trouxe uma visão mais abrangente e responsável para os acadêmicos envolvidos, superando o objetivo estabelecido anteriormente para as atividades, considerando que eles passaram a vivenciar e, simultaneamente, refletir sobre o momento histórico inédito abordando a questão jurídica e social das relações parentais.

Palavras-chave: Covid-19; experiência pedagógica; pandemia; relações parentais.

\section{ABSTRACT}

This text provides an account of the pedagogical experience carried out in the extension practice of the Family Law discipline, in view of the need to adapt the planning of activities planned for the first half of 2020, due to the unexpected situation of social distancing imposed by the onset of the pandemic caused by Covid-19. The elaboration and publication of a collective research article, relating the extension project theme to the unexpected reality, brought a more comprehensive and responsible view to the academics involved, surpassing the previously established objective for the activities, considering that they started to experience and, simultaneously, reflect on the unprecedented historical moment addressing the social and legal issue of parental relationships.

Keywords: Covid-19; teaching experience; pandemic; parental relationships

\footnotetext{
1 Relato, em forma de texto especial, de experiência pedagógica desenvolvida no primeiro semestre de 2020 na atividade de extensão dentro da disciplina de Direito das Famílias, do Curso de Direito, da Universidade Franciscana 2 Mestre em Direito pela UNISC, professora de Direito das Famílias e Sucessões da UFSM. E-mail: bernadete@prof.ufn.edu.br.
} 


\section{INTRODUÇÃO}

O mundo foi tomado de surpresa frente a um dos maiores fenômenos da história contemporânea, quando, no final do ano de 2019, iniciou na China a transmissão de um vírus nominado Sars-Cov-2, que provoca a doença Covid-19. A partir desse fato, foi desencadeada uma pandemia declarada oficialmente pela Organização Mundial da Saúde (OMS) em 11 de março de 2020.

Em virtude do alto índice de contágio, acelerada disseminação e gravidade da doença, foi recomendado pela OMS o isolamento ou distanciamento social não somente para evitar a transmissão, mas para que os países pudessem preparar seus sistemas de saúde com materiais, equipamentos, leitos e recursos humanos aptos para o enfrentamento da pandemia. Dessa forma, em todo o território nacional permaneceram em funcionamento apenas as chamadas "atividades essenciais", sendo que as famílias se isolaram em suas residências, vivenciando o que popularmente foi nominado de "quarentena".

Tal situação atingiu fortemente o ensino presencial e, de forma preponderante, as atividades acadêmicas extensionistas que demandam contato direto com a sociedade. Como parte do Programa de Extensão Institucional da Universidade Franciscana (UFN) "Direito, políticas públicas e diversidade" e do Projeto de Extensão Integrador "Direito Constitucional Aplicado", do Curso de Direito, desde o ano de 2019, a disciplina de Direito das Famílias vinha desenvolvendo um trabalho de caráter extensionista, voltado para a comunicação direta com a sociedade através de encontros presenciais, tendo como foco "Os efeitos do rompimento conjugal na convivência parental: a conscientização da importância da guarda compartilhada como prevenção à alienação parental e ao abandono afetivo".

Entre os objetivos propostos, estava a intervenção acadêmica na comunidade local e regional, na busca de uma cultura pela paz nas relações parentais em situações de pós-dissolução das famílias. Assim, o objeto principal era a divulgação e valorização da guarda compartilhada. como meio de prevenção à alienação parental e ao abandono afetivo. Os instrumentos previstos para essa comunicação era a promoção de encontros junto às comunidades organizadas como escolas, clubes, agremiações, sindicatos e outros grupos sociais, bem como a utilização da rede social como meio de divulgação.

Considerando-se a nova e inusitada situação de isolamento social, fez-se necessário readequar o projeto e buscar novas formas da participação e intervenção social acadêmica. Surgiu então a proposta de conhecer e divulgar os efeitos da pandemia nas relações familiares, com estudo da doutrina e da jurisprudência produzida naquele período e, após, divulgar-se amplamente os resultados com intuito colaborativo e educativo. Para tanto, delimitou-se como tema de pesquisa os impactos gerados pelo isolamento social e a crise econômica advinda em razão da pandemia de 2020, nas questões atinentes ao Direito das Famílias.

Em conjunto com os acadêmicos, planejou-se a elaboração de um artigo coletivo com participação de voluntários entre os matriculados na disciplina, a partir do seguinte problema: Considerando 
que a pandemia ocorrida em 2020 afetou acentuadamente as relações familiares, inclusive àquelas já regulamentadas em acordos ou sentenças judiciais, questiona-se: - Qual o papel do Direito das Famílias na apreciação dos novos litígios que se formam a partir desse fenômeno imprevisível? - Quais os aspectos das relações familiares judicializadas foram afetadas frente ao isolamento social e à crise econômica? Como a atual jurisprudência tem se posicionando frente às questões inéditas que se apresentaram?

O presente relato, em forma de "texto especial", pretende demonstrar o resultado da experiência pedagógica realizada, socializando o trabalho desenvolvido, considerando o seu ineditismo e forma emergencial de criação.

\section{METODOLOGIA}

A súbita necessidade de replanejamento do subprojeto de extensão proposto para a disciplina de Direito das Famílias, trouxe a necessidade da busca de novas possibilidades para que os acadêmicos matriculados no primeiro semestre de 2020 pudessem participar das atividades extensionistas. Dessa forma, optou-se pela elaboração de um artigo acadêmico produzido coletivamente, com a participação dos alunos e coordenado pela professora, possibilitando-se o engajamento do grupo de forma diferenciada.

Inicialmente foi elaborado um plano de trabalho a ser inserido como adendo ao plano original da atividade extensionista, onde foram apresentadas as justificativas para a alteração, a nova delimitação do trabalho, os seus objetivos gerais e específicos, uma revisão bibliográfica sobre o tema, bem como o plano provisório do artigo, cronograma das atividades e metodologia a ser observada.

A construção do artigo ocorreu na forma coletiva, com participação direta de cinco acadêmicos voluntários matriculados na disciplina, selecionados após prévia inscrição, sob a coordenação da professora da disciplina. Os textos parciais, na forma de fichas de leitura, foram enviados para a coordenação do grupo em fluxo contínuo, e aproveitados nas diferentes partes do artigo com observância das regras da Associação Brasileira de Normas Técnicas (ABNT). As informações alimentaram o texto nas suas diferentes partes, sendo que, à medida em que iam sendo apresentadas, o conteúdo era selecionado e organizado pela equipe. Ao final, a introdução e a conclusão foram elaboradas pelos alunos com supervisão direta da professora orientadora.

Com a sua finalização, o texto final do artigo foi disponibilizado para avaliação e apresentação de sugestões pelo grupo formado e, posteriormente, aprovado para ser socializado aos demais acadêmicos matriculados na disciplina.

A comunicação entre o grupo se deu através de correspondência eletrônica, onde o texto formulado ia sendo disponibilizado à medida em que era modificado, bem como através de mensagens, via WhatsApp, em grupo formado no aplicativo com essa finalidade específica. 
Com a redação final aprovada, o texto foi disponibilizado na rede social nas páginas do projeto (Facebook e Instagram) ${ }^{3}$ bem como no grupo de estudos da turma com sítio no Facebook. A participação dos alunos participantes foi valorizada na sua nota dentro da disciplina de Direito das Famílias, correspondente à terceira avaliação do primeiro semestre de 2020.

As fontes das informações foram buscadas na doutrina especializada, principalmente às disponibilizadas na internet, considerando a contemporaneidade e o ineditismo do tema. Foram analisadas as decisões jurisprudenciais construídas pelo Tribunal de Justiça do Rio Grande do Sul (TJ-RS) no período da pesquisa, bem como acompanhamento de lives, entrevistas, artigos e demais notícias referentes ao assunto delimitado.

Os demais alunos, matriculados na disciplina de Direito das Famílias, ainda que não tenham participado diretamente da elaboração do artigo, colaboraram com o envio de materiais, apresentação de sugestões e informações pertinentes.

Ao final do semestre letivo, foi apresentado o artigo construído para as duas turmas participantes, com promoção de debates acerca do material nele produzido e, posteriormente, o texto foi disponibilizado na rede social.

\section{DESENVOLVIMENTO}

O acompanhamento dos fenômenos sociais faz parte do ensino-aprendizagem na área das Ciências Humanas e Sociais, notadamente no Curso de Direito, onde se objetiva a formação de um cidadão crítico, reflexivo e participante em sua comunidade. Para tanto o engajamento do acadêmico nas questões sociais deve ser privilegiada na sua formação, oportunizando-se não somente o conhecimento das questões, mas também a sua reflexão crítica e intervencionista.

A professora Judith Martins Costa, analisando os trabalhos acadêmicos sobre a crise no Direito, concluiu pela necessidade de seu aprimoramento pelo fato de estarem fundamentalmente baseados na transmissão do resultado da prática jurídica dos operadores jurídicos e não na produção acadêmica desenvolvida segundo critérios de pesquisa científica. Para a professora e doutrinadora essa é uma peculiaridade que provoca a confusão entre a prática e a pesquisa, que, segundo ela, devem estar amalgamadas não de forma circular, mas espiralada, sempre com um elemento novo que acresce (COSTA, 2005, p. 38).

A experiência de um trabalho curricular extensionista se constituiu num espaço diferenciado para a construção do conhecimento e de reflexão sobre a disciplina Direito das Famílias, adequando-se ao seus principais objetivos que são: oportunizar aos acadêmicos de Direito o conhecimento, debate e

3 Através de páginas no Instagram (extensao_quem_ama_cuida) e no Facebook (Quem ama cuida- pela boa convivência parental), os acadêmicos participantes do Subprojeto de extensão na disciplina de Direito das Famílias preparam e divulgam os conteúdos usando os vários recursos disponibilizados pelos aplicativos. São publicadas decisões jurisprudenciais, notícias atualizadas, textos legislativos e doutrinários, produção acadêmica pertinente, sugestões de filmes e livros, atividades de interação motivadoras, lives com debates e entrevistas com operadores jurídicos e especialistas das áreas afins. 
reflexão sobre o direito das famílias brasileiro, tanto no que tange à dogmática jurídica, quanto em seu aspecto prático e crítico, tendo presente o desenvolvimento legislativo e jurisprudencial, bem como aplicar a prática extensionista junto à disciplina, com vistas a formar operadores jurídicos sensíveis aos problemas e busca de resoluções, intervindo na comunidade local e regional.

O subprojeto de extensão, que foi readequado em função da situação excepcional do distanciamento social, já apresentava em seu planejamento a importância do envolvimento da universidade nas questões de litígios familiares que afetam a sociedade como um todo, com o papel de informar à sociedade através da divulgação da legislação e da conscientização de sua importância e efeitos, promovendo assim o papel social da academia.

A situação-problema apresentada para a atuação extensionista, mencionava a carência do Poder Judiciário nos meios de prevenção, ou de rápido diagnóstico, das condutas litigantes que afetam os membros de uma família, em especial crianças e adolescentes. A incidência desses casos pode ser aferida pelo número de registros policiais e ações judiciais específicas sobre descumprimentos de acordos e sentenças referentes à convivência parental, gerando sofrimento moral e físico nas suas vítimas. Como forma preventiva para o problema, bem como em atendimento aos princípios constitucionais atinentes, a legislação prevê a guarda dos filhos na modalidade compartilhada entre os genitores como sendo a regra geral nos processos de dissolução dos casamentos e das uniões estáveis. Porém, verifica-se um grande desconhecimento a respeito do assunto e mesmo de sua importância, o que interfere diretamente na eficácia e no objetivo desse instituto.

A universidade, em especial o Curso de Direito através da disciplina de Direito das Famílias, tem condições e responsabilidade na busca da mudança desse comportamento e conscientização sobre o tema, através de um trabalho de extensão. Apropriando-se do conhecimento do assunto, através do estudo teórico e jurisprudencial a respeito, bem como da troca de experiências trazida pela prática dos estágios e vivência profissional dos operadores jurídicos que atuam na área, é possível habilitar os alunos da disciplina, para difundir e conscientizar a população no sentido de facilitar a boa convivência parental, evitando os efeitos prejudiciais aos "filhos do divórcio".

Com o advento da pandemia, esses litígios se acentuaram, em especial pelo isolamento social, sendo comprovado o aumento de número de divórcios e os efeitos que dele advém. Frente à nova realidade e considerando a suspensão das atividades presenciais na UFN, readequou-se os objetivos do subprojeto de extensão vinculado à disciplina, voltando-se de forma específica para o fenômeno social que então se apresentou. Foi assim que surgiu a proposta de criação de um artigo coletivo, com objetivo geral de análise do fenômeno da pandemia nas relações parentais e seus efeitos frente aos acordos e sentenças judiciais na área do Direito das Famílias.

Houve a preocupação na apresentação de uma justificativa convincente sobre a alteração do planejamento e o interesse despertado para a pesquisa, acompanhando-se a produção jurídica acerca do momento inédito e a relevância do tema a ser estudado. 
Para a professora Sandra Maria Nascimento de Mattos, justificar é necessário para dar credibilidade às intenções pretendidas pelos pesquisadores na geração de novos conhecimentos.

A justificativa de pesquisa aborda a razão pela qual a pesquisa se faz necessária. Expõe, também, a lacuna existente em relação ao tema escolhido e esclarece o motivo de buscar uma solução para o problema encontrado. Nessa perspectiva, a justificativa respalda a importância teórico-prática da construção de um novo conhecimento e caracteriza a intenção do pesquisador. O objetivo inicial de uma justificativa é caracterizar e mostrar a relevância do tema, tal qual apresentar o motivo inicial do pesquisador em relação ao tema. Dessa forma, o pesquisador vai apresentar argumentos convincentes que dão possibilidades para o desenvolvimento da pesquisa (MATTOS, 2020, p. 170).

$\mathrm{Na}$ apresentação do artigo, que foi intitulado "Os efeitos da pandemia e o distanciamento social nas relações familiares à luz do Direito das Famílias", foi apresentada a seguinte justificativa:

A nova e imprevisível situação tem provocado grande inquietação na área de Direito das Famílias, eis que interfere no direito de convivência entre pais, filhos e avós, demandando incerteza na aplicabilidade ou não dos acordos de convivência e decisões judiciais sobre as questões. Ainda desponta a grave crise econômica em virtude das medidas tomadas, sendo que várias determinações legais têm sido promulgadas, além de projetos de lei que pretendem regulamentar as questões afetas ao problema. Tais medidas atingem o pagamento das pensões alimentícias, bem como as formas de cobrança pelo descumprimento das obrigações estabelecidas. Esses importantes fatores interferem diretamente no Direito das Famílias normatizado, bem como, modifica a jurisprudência solidificada no decorrer dos anos, o que motivou a elaboração do presente artigo coletivo, envolvendo acadêmicos do Curso de Direito da UFN, na prática extensionista da disciplina de Direito das Famílias. O presente trabalho de pesquisa visa analisar o fenômeno da pandemia provocada pelo COVID-19 e seus efeitos, nas seguintes questões: o fenômeno do isolamento social e seus efeitos nas relações parentais que envolvem casais, filhos e relação avoenga; a questão da imprevisibilidade nos acordos e sentenças judiciais que regulamentam as convivência parental entre pais separados e filhos; os efeitos do isolamento social na guarda compartilhada e convivência parental; os efeitos do isolamento nas relações avoengas; a possibilidade da Ação Revisional de Alimentos e Cumprimentos de Sentença pelo não pagamento da obrigação, frente aos efeitos econômicos oriundos das medidas tomadas pelo Estado em função da pandemia; a aplicação do princípio da menor intervenção estatal nas relações familiares, frente às medidas tomadas em função da pandemia. Além do levantamento da doutrina a respeito do assunto e manifestações dos estudiosos sobre o tema, também foi efetuado um levantamento das decisões jurisprudenciais e da legislação vigente acerca dos efeitos da pandemia e isolamento social nas relações familiares, no período dos meses de março a junho de 2020 (SANTOS, 2021).

A intercomunicação constante entre os acadêmicos permitiu uma participação cooperativa no processo educacional, num processo emancipatório de criação. Considerando o ineditismo dos temas trabalhados, a atuação constante dos participantes passou a ser, não somente de relatores do conhecimento produzido, mas testemunhas dessa produção, eis que o momento da pandemia acarretou numa produção jurídica inédita, doutrinária e jurisprudencial, que foi sendo feita e refeita, num processo dialético, na busca do aperfeiçoamento, o que pode ser acompanhado contemporaneamente pelos acadêmicos pesquisadores. 
Percebeu-se assim a efetiva construção do conhecimento, numa concepção traduzida por Paulo Freire como uma leitura crítica do mundo que provoca mudanças na própria percepção dos agentes envolvido no processo de aprendizagem. Ensinar, segundo o educador, não é transferir conhecimento, mas criar possibilidades para que o educando tenha suas próprias produções e construção do saber apreendido nos aspectos políticos, éticos, epistemológicos, ontológicos e pedagógicos, necessitando também ser constantemente vivido e testemunhado (FREIRE, 2011, p. 48).

Como objetivo geral na produção da pesquisa acadêmica, estabeleceu-se a análise do fenômeno da pandemia ocorrida em 2020 e seus efeitos frente aos acordos e sentenças judiciais que regram as relações parentais. Foram definidos como objetivos específicos: estudar o fenômeno do isolamento social e seus efeitos nas relações parentais que envolvem casais, filhos e relação avoenga; analisar a questão da imprevisibilidade nos acordos e sentenças judiciais que regulamentam as convivência parental entre pais separados e filhos; identificar os efeitos do isolamento social na guarda compartilhada e convivência parental e nas relações avoengas; verificar a possibilidade da Ação Revisional de Alimentos e Cumprimentos de Sentença pelo não pagamento da obrigação, frente aos efeitos econômicos oriundos das medidas tomadas pelo estado em função da pandemia; verificar a aplicação do princípio da menor intervenção estatal nas relações familiares frente às medidas tomadas em função da pandemia e, por fim, efetuar um levantamento das decisões jurisprudenciais no TJ-RS acerca dos efeitos da pandemia e isolamento social nas relações familiares, no período dos meses de março a junho de 2020.

Na conclusão do artigo coletivo, os acadêmicos pesquisadores expressaram a necessidade de que uma certa dose de humildade deve ser apreendida pelos profissionais do Direito das Famílias, na medida em que se torna evidente a insuficiência de instrumentos jurídicos, por melhor que as previsões legais possam parecer, para se acompanhar e aperfeiçoar as relações existenciais no caso dos litígios familiares judicializados. Assim, impõe-se a necessidade do estudo específico em cada caso concreto, bem como da necessária empatia e bom senso no trato das questões familiaristas por parte dos magistrados e demais operadores do Direito.

A elaboração de um artigo coletivo, envolvendo pesquisa e redação por acadêmicos engajados, além de promover a própria divulgação do conhecimento adquirido através da publicação acadêmica, constituiu uma forma de desenvolver uma atividade curricular extensionista, no momento que foi disponibilizado o material pesquisado para a comunidade em geral, cumprindo-se assim o objetivo de formação de operadores jurídicos sensíveis aos problemas sociais, intervindo na comunidade local e regional.

Com a apropriação do conhecimento que foi sendo produzido no decorrer do primeiro semestre de 2020 e pela análise e estudo das decisões judiciais que foram sendo publicadas, a intervenção acadêmica feita através da pesquisa na área e sua divulgação com intuito educativo, foi extremamente relevante, atingindo satisfatoriamente os objetivos buscados. 


\section{CONCLUSÃO}

Ainda que, num momento inicial, a imprevisível alteração das atividades curriculares, imposta pelo distanciamento social tenha trazido um momento de inquietação, o ensino à distância fez com que se estabelecesse uma cumplicidade entre professores e alunos, na busca das soluções adequadas para o enfrentamento das dificuldades que então se apresentaram.

Através de um trabalho cooperativo entre um grupo voluntário de alunos e a professora da disciplina, foram somados esforços para que a proposta pré-existente da atividade curricular extensionista não fosse prejudicada na sua totalidade. Para tanto, a curiosidade acadêmica despertada pelas questões inéditas que se apresentaram, motivou a busca do conhecimento das soluções encontradas no meio jurídico no enfrentamento dos novos problemas, eis que era evidente o possível acirramento dos litígios familiares nas dissoluções das uniões conjugais em virtude da forte crise global que se estabeleceu. Nasceu dessa forma a nova proposta de trabalho aqui relatada.

Com a facilidade de acesso aos meios de comunicação disponíveis pela internet, foi possível desenvolver o trabalho proposto sem maiores dificuldades. $\mathrm{O}$ envio de material para aproveitamento no artigo coletivo superou as expectativas, provocando uma seleção minuciosa do conteúdo, resultando em um artigo mais extenso do que o anteriormente planejado. Ainda assim, procurou-se aproveitar ao máximo todas as contribuições, com o intuito de valorizar as participações, tanto do grupo diretamente responsável pelo desenvolvimento do trabalho, quanto dos demais alunos da disciplina.

O conhecimento produzido e sistematizado no artigo construído coletivamente foi aproveitado nas aulas ministradas de Direito das Famílias, sendo que, especialmente a jurisprudência coletada, serviu de exemplo no decorrer do desenvolvimento do conteúdo da disciplina.

De forma especial, o mérito do trabalho desenvolvido foi a evidente integração dos alunos e engajamento responsável e ativo nas atividades. O ineditismo da matéria abordada fez com que se evidenciasse o estímulo à pesquisa. Considerando que o objeto de estudo se constituía em produções jurídicas inéditas e contemporâneas, os acadêmicos tiveram a oportunidade de acompanhar o dinamismo das relações sociais e a tentativa do Direito em acompanhar essas mudanças. Pode-se citar, como exemplo, as decisões judiciais que, no decorrer dos meses, foram se modificando e se aperfeiçoando à medida em que a situação fática passava a ser melhor compreendida. Tais mudanças foram observadas pelos acadêmicos pesquisadores, que, na sua conclusão, destacaram a necessidade do minucioso e efetivo exame de cada caso concreto para a tomada da decisão judicial.

Pode-se avaliar a experiência pedagógica como extremamente válida e produtiva, eis que, além do aperfeiçoamento de um trabalho pedagógico, também permitiu o alcance da busca pela formação de futuros operadores do Direito críticos, criativos, conciliadores e conscientes da responsabilidade na intervenção social na busca de uma cultura de paz. 


\section{REFERÊNCIAS}

COSTA, Judith Martins. O que é a pesquisa em Direito-Parte 1.1. in NOBRE, Marcos, et al. O que é a pesquisa em Direito? São Paulo: Quartier Latin, 2005. p. 38-46

FREIRE, Paulo. Pedagogia da autonomia: saberes necessários à prática educativa. 43 ed. São Paulo: Paz e Terra, 2011

MATTOS, Sandra Maria Nascimento de Conversando sobre metodologia da pesquisa científica. Porto Alegre, RS: Editora Fi, 2020, p.170.

SANTOS, Bernadete Schleder et al. Os efeitos da pandemia e o distanciamento social nas relações familiares à luz do Direito das Famílias. Disponível em https://bit.ly/3qbz42z. Acesso em: 22 jun. 2021. 